\title{
Acute disseminated encephalomyelitis after SARS-CoV-2 infection
}

Neurol Neuroimmunol Neuroinflamm 2021;8:e949. doi:10.1212/NXI.0000000000000949

In the Clinical/Scientific Note "Acute disseminated encephalomyelitis after SARS-CoV-2 infection" by Novi et al., ${ }^{1}$ there is an error in the opening paragraph. The first sentence should read, "Acute disseminated encephalomyelitis (ADEM) is a rare autoimmune disease of the CNS, that often develops after viral infections and mainly affecting children." The publisher regrets the error.

\section{Reference}

1. Novi G, Rossi T, Pedemonte E, et al. Acute disseminated encephalomyelitis after SARS-CoV-2 infection. Neurol Neuroimmunol Neuroinflamm 2020;7:e797. doi:10.1212/NXI.0000000000000797. 


\title{
Neurology \\ Neuroimmunology \& Neuroinflammation
}

\author{
Acute disseminated encephalomyelitis after SARS-CoV-2 infection \\ Neurol Neuroimmunol Neuroinflamm 2021;8; \\ DOI 10.1212/NXI.0000000000000949
}

This information is current as of December 15, 2020

\section{Updated Information \& \\ Services}

References

Permissions \& Licensing

Reprints including high resolution figures, can be found at:

http://nn.neurology.org/content/8/1/e949.full.html

This article cites 1 articles, 1 of which you can access for free at: http://nn.neurology.org/content/8/1/e949.full.html\#\#ref-list-1

Information about reproducing this article in parts (figures,tables) or in its entirety can be found online at:

http://nn.neurology.org/misc/about.xhtml\#permissions

Information about ordering reprints can be found online: http://nn.neurology.org/misc/addir.xhtml\#reprintsus

Neurol Neuroimmunol Neuroinflamm is an official journal of the American Academy of Neurology.

Published since April 2014, it is an open-access, online-only, continuous publication journal. Copyright $@$ 2020 American Academy of Neurology. All rights reserved. Online ISSN: 2332-7812.

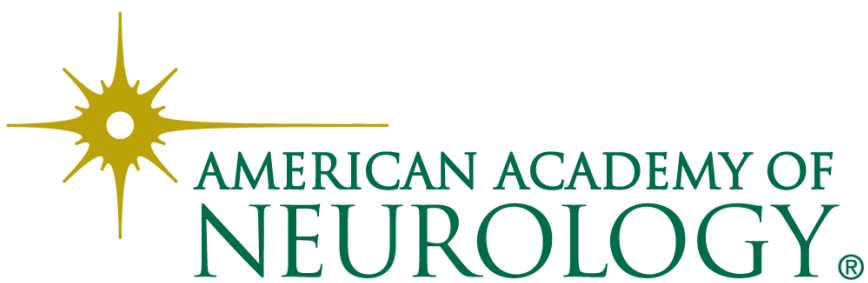

